\title{
The Relationship between Leaf Enclosure, Transpiration, and Upper Leaf Necrosis on Lilium 'Star Gazer'
}

\author{
Yao-Chien Chang ${ }^{1}$ and William B. Miller ${ }^{2}$ \\ Department of Horticulture, Cornell University, Ithaca, NY 14853-5904
}

\begin{abstract}
AdDitional INDEX wORDs. lily, calcium deficiency disorders, calcium nutrition, leaf scorch, tipburn, leaf burn, lysimeter
Abstract. Upper leaf necrosis (ULN) on Lilium 'Star Gazer' has been shown to be a calcium (Ca) deficiency disorder. Initial symptoms of ULN tend to appear on leaf margins. Before flower buds are visible, young expanding leaves are congested and overlap each other on the margin. In the current study, we examined the relationship between leaf enclosure, transpiration, and upper leaf necrosis. We demonstrated that low transpiration rate and enclosure of young leaves played an important role in the occurrence of ULN. Young expanding leaves are low transpiration organs. The younger the leaf, the lower the transpiration rate and Ca concentration. Leaf enclosure further reduced transpiration of these young leaves and promoted ULN. Upper leaf necrosis was suppressed by manually unfolding the leaves using a technique we refer to as artificial leaf unfolding (ALU). ALU minimized leaf congestion, exposing leaves that were previously enclosed. We demonstrated that the effect of ALU was not the consequence of thigmomorphogenesis, as ULN was not reduced by mechanical perturbation in lieu of ALU. With ALU, transpiration of upper leaves was significantly increased and Ca concentration of the first leaf immediately below the flower buds was increased from $0.05 \%$ to $0.20 \%$. We concluded that leaf enclosure promoted ULN occurrence, and ALU suppressed ULN primarily by increasing transpiration. The use of overhead fans to increase airflow over the tops of the plants significantly reduced both ULN incidence and severity.
\end{abstract}

Calcium $(\mathrm{Ca})$ deficiency disorders occur in many economically important crops (Shear, 1975), and upper leaf necrosis (ULN) on Lilium 'Star Gazer' has been demonstrated recently to be another example (Chang, 2002). For the plants grown from 16- to $18-\mathrm{cm}$ bulbs, ULN symptoms began to exhibit on upper leaves $\approx 30 \mathrm{~d}$ after planting (DAP) and no further symptoms developed after flower buds were visible ( $\approx 50$ DAP) (Chang, 2002). Only upper leaves that were enclosed during enlargement were susceptible to ULN. The symptoms started to develop when these leaves were still enclosed. These susceptible upper leaves are the leaves associated with flower buds and about five to seven leaves directly beneath the flower buds. Of them, the leaf U1 (first leaf under flower buds) is most susceptible (Chang, 2002). The primary cause of ULN is an insufficient Ca supply from the bulb (Chang and Miller, 2003). At the stage when initial symptoms of ULN appear, there is abundant Ca present in the soil mix (Chang, 2002). However, the young leaves are not able to obtain enough $\mathrm{Ca}$ from the soil as well as from the bulb scales, so that a transient or induced calcium deficiency results. Since ULN symptoms occur only on young, expanding upper leaves and initially on leaf margins, it is suspected that leaf enclosure (overlap of expanding leaves) is a key factor encouraging ULN development.

Received for publication 3 Apr. 2003. Accepted for publication 6 Oct. 2003. This paper is based on a portion of the $\mathrm{PhD}$ dissertation submitted by Y.C. Chang. Use of trade names does not imply endorsement of named products nor criticism of similar ones not named. We thank Thomas H. Whitlow, Timothy L. Setter, Leon V. Kochian, and Garry Legnani of Cornell University for their sound advice on this project. This research was funded in part through a Specific Cooperative Agreement between the USDA-ARS Plant Protection Research Unit and the Cornell Department of Plant Pathology, Ithaca, N.Y. (SCA \# 58-1907-0-035) funded by the USDA-ARS as part of the Floriculture and Nursery Research Initiative. We gratefully acknowledge the financial and material support from the Ministry of Education, Taiwan, the Fred C. Gloeckner Foundation, the Kenneth Post-Herman Schenkel Memorial Council, and the Royal Dutch Wholesalers' Association for Flowerbulbs and Nursery Stock.

${ }^{1}$ Former graduate research assistant, held a scholarship from the Ministry of Education, Taiwan. Currently postdoctoral research associate.

2Professor and corresponding author; email: wbm8@cornell.edu.
In general, $\mathrm{Ca}$ deficiency disorders are the result of uneven $\mathrm{Ca}$ distribution within a plant, rather than insufficient $\mathrm{Ca}$ uptake from the soil (Bradfield and Guttridge, 1984; Kirkby and Pilbeam, 1984). One major cause of blossom-end rot in tomato is that the fruit are less competitive than leaves for the available $\mathrm{Ca}$ (Ho et al., 1993). A number of environmental factors affect Ca partitioning between organs; of them, transpiration is crucial. In plants, $\mathrm{Ca}$ is transported mainly by the xylem, thus, a high rate of xylem flow into desired organs is required to supply adequate $\mathrm{Ca}$ (Marschner, 1995). The rate of calcium influx to young tissues is mainly affected by transpiration during the day and root pressure during the night (Bradfield and Guttridge, 1984; Everaarts and Blom Zandstra, 2001; Guttridge et al., 1981; Wiebe et al., 1977). Many studies have shown that transpiration and Ca concentration in organs are positively correlated (Barta and Tibbitts, 1986; Goto and Takakura, 1992b; Palzkill and Tibbitts, 1977; Win et al., 1991). High humidity promotes Ca deficiency in many crops (Barta and Tibbitts, 1986; Goto and Takakura, 1992b; Murtadha et al., 1989).

Fleshy fruit and young leaves are characterized by low rates of transpiration, and Ca deficiency symptoms are common on these organs (Kirkby and Pilbeam, 1984; Marschner, 1995). Blossom-end rot on tomato fruit (Ho et al., 1993) and tipburn on inner lettuce leaves (Collier and Tibbitts, 1982) are two typical examples. Different organs in a plant compete for Ca by way of transpiration. Practically, transpiration management has been shown to be important for reducing $\mathrm{Ca}$ deficiencies: either to increase transpiration of desired organs (Goto and Takakura, 1992b), or to decrease transpiration of competing organs (Morzadec et al., 1998; Win et al., 1991). To increase Ca content in growing leaves or fruit, increasing transpiration was more effective than increasing Ca supply in the substrate (Kirkby, 1979; Marschner, 1995).

By flowing air onto inner, developing lettuce leaves, Goto and Takakura (1992a) prevented tipburn without sacrificing growth rate. Using ${ }^{45} \mathrm{Ca}$, they also demonstrated a 4.6-fold increase in $\mathrm{Ca}$ accumulation in the inner leaves with flowing air. The flowing air supply increased the vapor pressure deficit in the air around 
the inner leaves, thus increasing transpiration, and consequently promoting Ca movement to the inner leaves (Goto and Takakura, 1992b). Overhead fans have become a practical method to reduce the risk of tipburn in lettuce, and might hold similar promise for lilies.

The objective of current study is to clarify the relationship between leaf enclosure, transpiration, and upper leaf necrosis. In addition, we wish to evaluate the use of overhead fans to increase air flow and minimize ULN. We also test the hypothesis that there is a critical period for susceptibility during which control measures should be focused.

\section{Materials and Methods}

Several experiments were conducted to understand the relationship between leaf enclosure, transpiration, and ULN. Bulbs (16 to $18 \mathrm{~cm}$ in circumference) were planted in $15 \mathrm{~cm}$ plastic pots with 1 soil : 2 peatmoss : 1 perlite mix (by volume). Details of soil amendments, fertilization and cultural practices are reported elsewhere (Chang and Miller, 2003). The calcium concentration in the fertilizer solution used for irrigation was 67 $\mathrm{mg} \cdot \mathrm{L}^{-1}$. An unfolded leaf was defined as when $>75 \%$ of its leaf surface was not in contact with other leaves (as shown in Fig. 1); therefore, an unfolded leaf is not enclosed by other leaves and can transpire freely. When the term upper leaves is used, it refers to the leaves on the upper one-third of the plant. To investigate if leaf enclosure increased ULN incidence, artificial leaf unfolding (ALU) was applied as a treatment in several experiments. ALU is the gentle, manual bending of leaves to a horizontal position in order to place them in an unfolded configuration several days earlier than they normally would unfold. After ALU, leaf enclosure was minimal and the young leaves were exposed as shown in Fig. 1. ALU was applied once or twice daily, as the artificially unfolded leaves were again somewhat congested the following day due to expansion and recoil, although not as much as in the control group. ALU was applied during a hypothesized 25 -d susceptible period, between the time when plant height is $\approx 25 \mathrm{~cm}$ and visible bud stage. ULN severity of a single leaf was determined by an index from 0 (healthy) to 5 based on necrosed leaf area: $0=$ no visible necrosis symptoms, $1=$ chlorotic spots, $2=$ curled leaf margin, $3=$ marginal necrosis, 4 $=$ dead leaf tip, and $5=>50 \%$ of the leaf area was necrotic. Single leaf severity of each leaf was then summed to give whole plant severity. When whole plant severity was $<5$, the symptoms were very light, and would not be visible to the casual observer.

EXPERIMENT 1: EFFECT OF LEAF POSITION ON STOMATAL CONDUCTANCE AND LEAF CALCIUM CONCENTRATION. Thirty bulbs $(62.4 \pm 1.6 \mathrm{~g}$ fresh weight) were planted on 9 July. Six plants were randomly selected 43 DAP (the stage when initial symptoms appeared) for stomatal conductance measurement. Stomatal conductance of 8 leaves at different locations (the two leaves associated with the 4th flower bud, the two leaves associated with the 1 st flower bud, the $5^{\text {th }}, 10^{\text {th }}$, $15^{\text {th }}$, and $20^{\text {th }}$ leaf directly beneath the flower buds) was measured by a LI-1600 steady state porometer(LI-COR Inc., Lincoln, Nebr.) in the greenhouse under an average PAR (photosynthetically active radiation) of $350 \mu \mathrm{mol} \cdot \mathrm{m}^{-2} \cdot \mathrm{s}^{-1}$, temperature of $25^{\circ} \mathrm{C}$, and $\mathrm{RH}$ of $39 \%$. The leaves used for stomatal conductance measurement were then harvested, washed with reverse osmosis (RO) water to eliminate potential Ca contamination from fertigation. Leaves were rinsed in distilled water two times, and then oven-dried to constant weight at $70{ }^{\circ} \mathrm{C}$. Calcium concentration of the entire leaf was analyzed by inductively coupled plasma spectrometry (ICP) at a wavelength of $317.9 \mathrm{~nm}$.

EXPERIMENTS 2 AND 3: ARTIFICIAL LEAF UNFOLDING AND UPPER LEAF NECROSIS. On 7 Mar., 90 bulbs $(66.8 \pm 0.4 \mathrm{~g}$ fresh weight) were planted to investigate if leaf enclosure contributed to the occurrence of ULN. Treatments included artificially unfolding leaves 0,1 (in the afternoon), or 2 (morning, afternoon) times a day. ALU was applied from 33 to 56 DAP. The experiment was repeated with bulbs weighing $67.1 \pm 0.5 \mathrm{~g}$, which were planted on 11 May in another greenhouse; ALU was applied 31 to 56 DAP. In both experiments, a completely randomized experimental design (CRD) was used.

EXPERIMENT 4: EFFECTS OF ARTIFICIAL LEAF UNFOLDING, MECHANICAL PERTURBATION AND FOLIAR ETHEPHON SPRAYS ON UPPER LEAF NECROSIS. To test the hypothesis that the reduced ULN by ALU is not primarily attributed to thigmomorphogenesis, an experiment was conducted with treatments including ALU, mechanical perturbation, and foliar application of ethephon. Treatments were applied 20 to 45 DAP. For the ALU treatment,
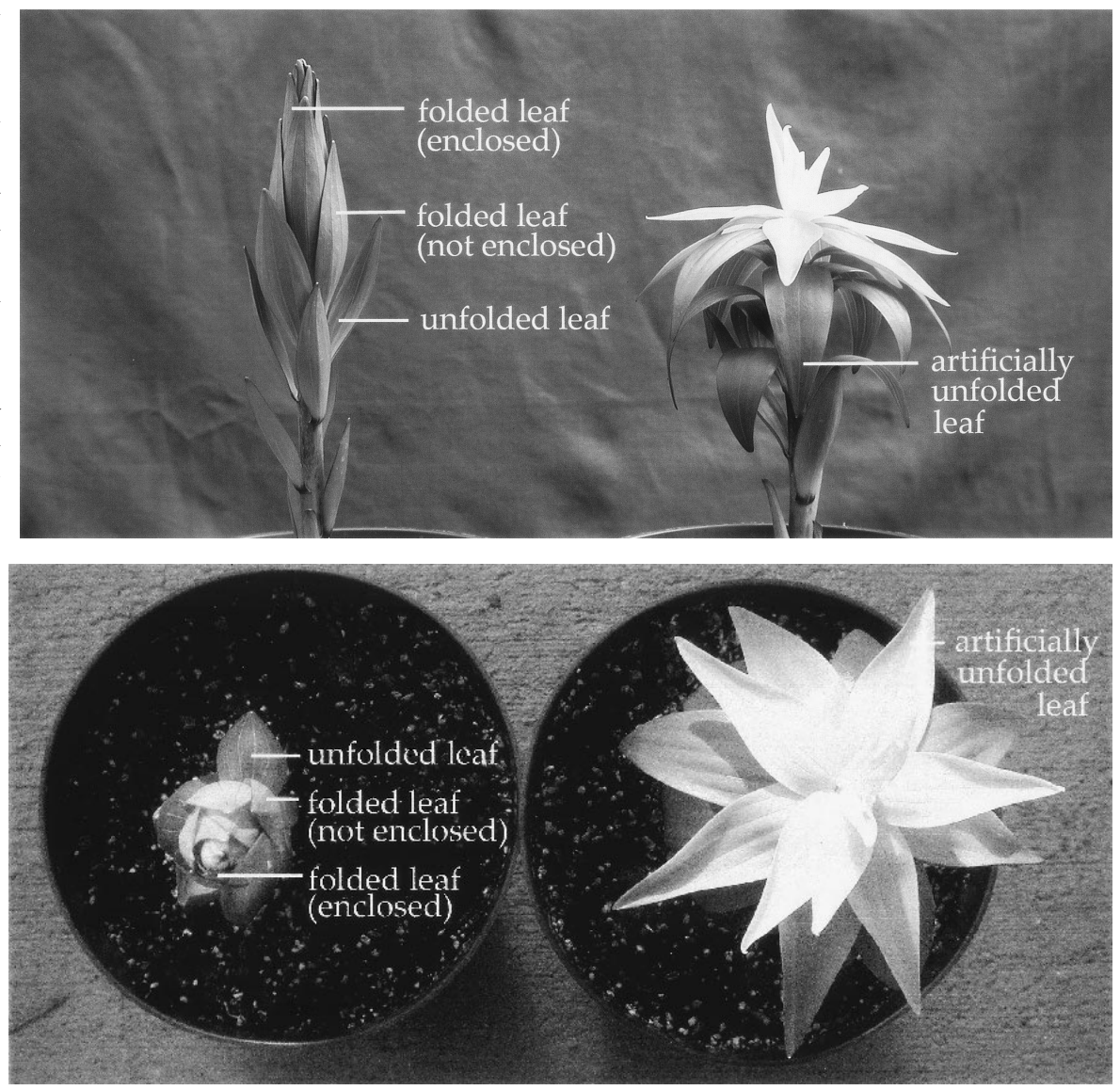

Fig. 1. Side (top) and top (bottom) views of leaf configuration in Lilium 'Star Gazer' with artificial leaf unfolding (ALU) (right) and without ALU (left). ALU is a manual bending of the leaves to a horizontal position to force them unfolded several days earlier. Examples of leaves that are folded, unfolded, enclosed, and not enclosed are indicated. 
Table 1. Effect of leaf position on stomatal conductance and leaf calcium concentration of Lilium 'Star Gazer'. Data were taken $43 \mathrm{~d}$ after planting; $\mathrm{n}=6$.

\begin{tabular}{|c|c|c|}
\hline $\begin{array}{l}\text { Leaf } \\
\text { location }\end{array}$ & $\begin{array}{l}\text { Stomatal conductance } \\
\left(\mathrm{mmol} \cdot \mathrm{m}^{-2} \cdot \mathrm{s}^{-1}\right)\end{array}$ & $\begin{array}{l}\text { Calcium conen } \\
\text { (\% dry wt })\end{array}$ \\
\hline Larger leaf associated with $4^{\text {th }}$ flower bud (L4F) & $43 \mathrm{~cd}$ & $0.67 \mathrm{e}$ \\
\hline Larger leaf associated with $1^{\text {st }}$ flower bud (L1F) & $78 \mathrm{~b}$ & $1.14 \mathrm{c}$ \\
\hline $5^{\text {th }}$ leaf under buds (U5) & $127 \mathrm{a}$ & $1.64 \mathrm{ab}$ \\
\hline $10^{\text {th }}$ leaf under buds (U10) & $107 \mathrm{a}$ & $1.81 \mathrm{a}$ \\
\hline
\end{tabular}

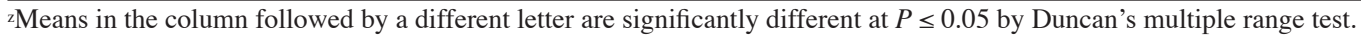

Table 2. Effect of artificial leaf unfolding on the occurrence of upper leaf necrosis on Lilium 'Star Gazer'; $\mathrm{n}=30$.

\begin{tabular}{lcc}
\hline Unfolding frequency & \multicolumn{2}{c}{ Necrosis $^{\mathrm{z}}$} \\
\cline { 2 - 3 } (times/day) & Incidence (\%) & Severity \\
\hline Expt. I, 7 March & 20.0 & $0.5 \mathrm{a}^{\mathrm{y}}$ \\
0 (control) & $0.0^{* *}$ & $0.0 \mathrm{~b}$ \\
1 & $0.0^{* *}$ & $0.0 \mathrm{~b}$ \\
2 & & \\
Expt. II, 11 May & 86.7 & $15.1 \mathrm{a}$ \\
0 (control) & $3.3^{* * *}$ & $0.5 \mathrm{~b}$ \\
1 & $0.0^{* * *}$ & $0.0 \mathrm{~b}$ \\
2 &
\end{tabular}

${ }^{2}$ Necrosis incidence is defined as the percentage of plants that have any level of symptom expressed. Necrosis severity of a plant is the sum of the severity indexes of individual leaves. The severity of each leaf is graded using a scale from 0 (healthy) to 5 ( $>50 \%$ of the leaf area was necrotic)

${ }^{y}$ Means in the column followed by a different letter are significantly different at $P \leq 0.05$ by Duncan's multiple range test.

*****Significantly different at $P \leq 0.01$ or 0.001 respectively, compared to control by chi-square test.

ALU was applied once a day. In the mechanical perturbation treatment, plants were touched twice a day by gently but rapidly moving hands from the lower leaves to the upper leaves. Each leaf received 20 touching events within $\approx 20 \mathrm{~s}$. For the ethephon treatment, $1,000 \mathrm{mg} \cdot \mathrm{L}^{-1}$ ethephon was sprayed to run-off twice during the experimental period, at $20 \mathrm{DAP}$, and again at 30 DAP. Each plant received $\approx 7 \mathrm{~mL}$ of ethephon solution per application. Each treatment had 30 single plant replicates in a CRD experimental design. The average fresh weight of bulbs was $59.6 \pm 0.5 \mathrm{~g}$.

EXPERIMENT 5: ARTIFICIAL LEAF UNFOLDING, TRANSPIRATION, AND CALCIUM. On 17 Dec., 60 bulbs $(64.1 \pm 0.6 \mathrm{~g})$ were planted in $10 \mathrm{~cm}$ pots and divided into control and ALU groups, with ALU being applied once daily from 24 to 49 DAP. Within each group, 15 plants were randomly selected for lysimeter weighing; another 15 plants remained intact for ULN observation. In the evening, 23 DAP, pots were wrapped with aluminum foil, and then the pot and all unfolded leaves were sealed inside a clear plastic bag. The weight of the plant plus the pot was recorded every evening at 6 PM for 8 successive days. Daily water loss from each plant was calculated by difference between days. During the lysimeter period (23 to $30 \mathrm{DAP}$ ), supplemental lighting by HID lamps was applied from 7:30 AM to 4:30 PM. Following the last lysimeter weighing (day 7, or $30 \mathrm{DAP}$ ), the upper leaves that were not sealed in the plastic bag were harvested. Leaf $\mathrm{Ca}$ concentration was analyzed by ICP as described above. Leaf U1 (first leaf under flower buds) was analyzed separately; all other upper leaves not sealed in the bag were combined and analyzed to represent the average value of the upper leaves. At this stage (day 7), about five leaves that were not sealed in the bag in the controls had naturally unfolded, while all the nonsealed upper leaves in the ALU group were already unfolded artificially. U1 leaves at day 7 were still folded in the control group, while in ALU group, they had been artificially unfolded for 2 to $4 \mathrm{~d}$. The experiment used a CRD experimental design. By using the lysimeter method and sealing the middle and lower leaves in the plastic bag, we were able to determine the increased transpiration of upper leaves caused by ALU.

EXPERIMENT 6: EFFECT OF OVERHEAD FANS. One hundred and eighty bulbs $(67.4 \pm 0.4 \mathrm{~g})$ were planted on 12 Oct. and placed in experimental chambers $(87 \mathrm{w} \times 87 \mathrm{~d} \times 146 \mathrm{~h} \mathrm{~cm})$ constructed with open sides and the front and back covered with clear polyethylene film. This film provided a barrier between treatments, as well as a barrier to airflow imposed when the greenhouse cooling fans were operating. A fan ( $23 \mathrm{~cm}$ in diameter) was installed on top of each chamber (at a height of $1.4 \mathrm{~m}$ ) to blow air vertically down to the canopy. Treatments were applied by turning the fans off, or to low, or high speed during the day (8 AM to 4 PM), from 5 to 65 DAP. Air flow above the canopy of each plant was measured by an air meter (RM-1X; Hastings-Raydist Inc, Hampton, Va.) at a height of $34 \mathrm{~cm}$. Each individual chamber was considered an experimental unit, and 20 plants were grown in each chamber. Each treatment had three replications (chambers) in a CRD experimental design. At the end of the experiment, necrosis incidence and severity data were collected. The mean of the 20 plants from each chamber was used as an observation for statistical analysis.

\section{Results}

Stomatal CONDUCtanCe and Calcium CONCENTRation at DIFFERENT LEAF LOCATIONS. Stomatal conductance of leaves at various morphological positions was measured 43 DAP. At 43 DAP, leaves of U5 (the fifth leaf below the first flower bud) and older were mature, L1F (the larger leaf associated with the first flower bud) was newly expanded, and leaves above L1F were still expanding. Table 1 shows that the stomatal conductance of young expanding leaves (S4F-S1F) were significantly lower than the mature leaves (U5 and older). Smaller leaves had lower stomatal conductance than larger leaves associated with the same flower bud. Stomatal conductance generally increased with leaf age until maturity. At the sampling stage, the leaves from position L1F to U10 were larger and had greater stomatal conductance; leaves between U15 and U20 were smaller, and leaves below U20 were very small scale leaves.

Calcium concentration at various leaf positions showed a similar trend with stomatal conductance: the higher the leaf's position 
Table 3. Effect of artificial leaf unfolding, mechanical perturbation, and foliar ethephon sprays on reducing upper leaf necrosis on Lilium 'Star Gazer'; $\mathrm{n}=30$.

\begin{tabular}{lcccc}
\hline & \multicolumn{2}{c}{ Necrosis $^{z}$} & \multicolumn{2}{c}{$\begin{array}{c}\text { Plant ht of } \\
(\mathrm{cm})\end{array}$} \\
\cline { 2 - 5 } Treatment & Incidence $(\%)$ & Severity & $74.4 \mathrm{a}$ & flower buds \\
\hline Control & 93.3 & $17.0 \mathrm{a}$ & $3.9 \mathrm{a}$ \\
Artificial leaf unfolding & $13.3^{* *}$ & $0.2 \mathrm{c}$ & $4.1 \mathrm{a}$ \\
Mechanical perturbation & $96.7^{\mathrm{Ns}}$ & $14.1 \mathrm{a}$ & $59.9 \mathrm{c}$ & $3.8 \mathrm{a}$ \\
Ethephon $\left(1000 \mathrm{mg} \cdot \mathrm{L}^{-1}\right)$ & $80.0^{\mathrm{Ns}}$ & $8.0 \mathrm{~b}$ & $52.9 \mathrm{~d}$ & $3.9 \mathrm{a}$ \\
\hline
\end{tabular}

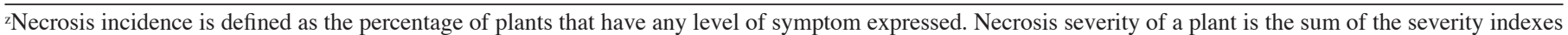
of individual leaves. The severity of each leaf is graded using a scale from 0 (healthy) to 5 ( $>50 \%$ of the leaf area was necrotic).

y Means in the column followed by a different letter are significantly different at $P \leq 0.05$ by Duncan's multiple range test.

ss,**Nonsignificant or significant at $P \leq 0.01$ compared to control by chi-square test.

Table 4. Effect of artificial leaf unfolding on upper leaf necrosis, transpiratin, and leaf calcium concentration in Lilium 'Star Gazer'. Leaves were harvested $30 \mathrm{~d}$ after planting and calcium concentration determined; $\mathrm{n}=15$.

\begin{tabular}{|c|c|c|c|c|c|c|}
\hline \multirow[b]{2}{*}{ Treatment } & \multicolumn{2}{|c|}{ Necrosis $^{z}$} & \multicolumn{2}{|c|}{ Transpiration } & \multicolumn{2}{|c|}{$\begin{array}{l}\text { Calcium concn } \\
(\% \text { dry wt })\end{array}$} \\
\hline & $\begin{array}{c}\text { Incidence } \\
(\%)\end{array}$ & Severity & $\begin{array}{c}\text { Daily } \\
\text { (g/plant/d) }\end{array}$ & $\begin{array}{c}\text { Day } 7 \\
\text { (g/plant/d) }\end{array}$ & $\begin{array}{l}\text { Leaf } \\
\text { U1y }\end{array}$ & $\begin{array}{c}\text { All other } \\
\text { upper leaves }\end{array}$ \\
\hline Control & 73.3 & $11.6 \mathrm{a}^{\mathrm{x}}$ & $3.4 \mathrm{~b}^{(P=0.006)}$ & $5.0 \mathrm{~b}^{(P=0.05)}$ & $0.05 \mathrm{~b}$ & $0.80 \mathrm{a}$ \\
\hline Artificial leaf unfolding & $0.0^{* * * *}$ & $0.0 \mathrm{~b}$ & $4.4 \mathrm{a}$ & $6.2 \mathrm{a}$ & $0.20 \mathrm{a}$ & $0.94 \mathrm{a}$ \\
\hline
\end{tabular}

${ }^{2}$ Necrosis incidence is defined as the percentage of plants that have any level of symptom expressed. Necrosis severity of a plant is the sum of the severity indexes of individual leaves. The severity of each leaf is graded using a scale from 0 (healthy) to 5 ( $>50 \%$ of the leaf area was necrotic).

yU1: the first leaf directly beneath the flower buds.

xMeans in the column followed by a different letter are significantly different at $P \leq 0.05$ by Duncan's multiple range test.

***Significantly different by chi-square test, $P \leq 0.0001$.

on the stem, the lower its $\mathrm{Ca}$ concentration (Table 1). Calcium concentrations were lower in expanding leaves (e.g., $0.29 \%$ for S4F and $0.67 \%$ for L4F). As leaves matured, Ca concentration increased. Therefore, middle and lower leaves (U5-U15) had a relatively high $\mathrm{Ca}$ concentration $(>1.5 \%)$ compared with younger upper leaves (Table 1). Leaf $\mathrm{Ca}$ concentration seemed to be a function of stomatal conductance and leaf age. This may explain why U10 had a lower stomatal conductance but higher Ca concentration, compared to that of U5 (Table 1). Calcium concentration in leaf U20 was lower than other middle and lower leaves, possibly a result from long-term shading by the upper canopy (Table 1).

ARTIFICIAL LEAF UNFOLDING SUPPRESSES UPPER LEAF NECROSIS. Whether applied once or twice per day, ALU successfully suppressed the occurrence of ULN (Table 2). With ALU, there were no plants with necrosis in Expt. I, and only 1 plant with necrosis in Expt. II (a total of 60 plants with ALU in each experiment). Artificial leaf unfolding resulted in shorter plants compared with controls, and plants with ALU applied twice per day were shorter than those given one daily application (data not shown). This observation led to the next experiment, investigating the possible involvement of thigmomorphogenesis and/or stress ethylene in the reduction of ULN by ALU.

EFFECTS OF ARTIFICIAL LEAF UNFOLDING, MECHANICAL PERTURBATION AND FOLIAR ETHEPHON SPRAYS ON UPPER LEAF NECROSIS. In this experiment, ALU, mechanical perturbation, and foliar ethephon sprays were used to determine if reduced ULN was the result of thigmomorphogenesis. Compared with untreated control plants, plant height was reduced in mechanical stress and ethephon spray treatments (Table 3). Plants treated with $1000 \mathrm{mg} \cdot \mathrm{L}^{-1}$ ethephon were shortest $(53 \mathrm{~cm})$, followed by mechanical perturbation $(60 \mathrm{~cm})$ and $\operatorname{ALU}(65 \mathrm{~cm})$, while controls averaged $74 \mathrm{~cm}$. Flower bud number was unaffected. All treatments, excepted ALU, showed a high incidence of ULN; only ALU reduced ULN incidence. The severity of ULN was very low in the ALU group, with an average severity of 0.2 (virtually unnoticeable). The ULN severity in the ethephon treatment was lower compared with control (8 and 17, respectively), although it was not as significant as in the ALU treatment (Table 3). These data indicate that the reduction of ULN by the ALU was not a consequence of thigmomorphogenesis.

Artificial leaf unfolding, transpiration and calcium. Similar to Expts. 2, 3, and 4, ALU successfully controlled the occurrence of ULN in this experiment (Table 4). No plants with necrosis were found in the ALU treatment, compared with an incidence of $73 \%$ in the control group. Daily transpiration of upper leaves in the ALU treatment was significantly greater than control plants: water loss was 4.4 and $3.4 \mathrm{~g} /$ plant, respectively (Table 4). As a result of an increasing number of unfolded (and thus transpiring) leaves, transpiration increased during the experiment (Fig. 2). On days 4 and 6, water losses were lower due to cloudy weather. Regardless, transpiration in the ALU group was significantly greater than controls.

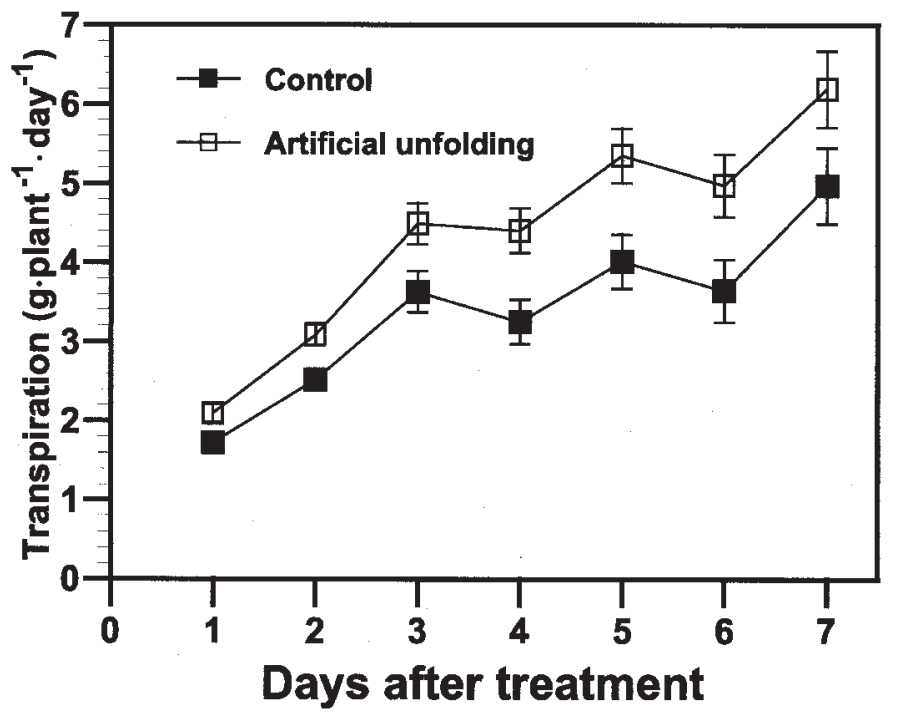

Fig. 2. Transpiration rates of upper leaves on Lilium 'Star Gazer' as affected by artificial leaf unfolding. Each point represents mean \pm SE of 15 replications. 
Table 5. Effect of increased airflow from overhead fans on reducing upper leaf necrosis on Lilium 'Star Gazer'. Data were analyzed from three observations; each observation was the mean of 20 plants.

\begin{tabular}{lccc}
\hline Fan & Air flow & \multicolumn{2}{c}{ Necrosis $^{\mathrm{z}}$} \\
\cline { 3 - 4 } setting & $\left(\mathrm{m} \cdot \mathrm{s}^{-1}\right)$ & Incidence $(\%)$ & Severity \\
\hline Off $($ control) & 0.09 & $88.3 \mathrm{a}^{\mathrm{y}}$ & $12.0 \mathrm{a}$ \\
Low speed & 0.75 & $68.3 \mathrm{~b}$ & $5.8 \mathrm{~b}$ \\
High speed & 0.97 & $58.3 \mathrm{c}$ & $6.3 \mathrm{~b}$ \\
\hline
\end{tabular}

${ }^{2}$ Necrosis incidence is defined as the percentage of plants that have any level of symptom expressed. Necrosis severity of a plant is the sum of the severity indexes of individual leaves. The severity of each leaf is graded using a scale from 0 (healthy) to 5 ( $>50 \%$ of the leaf area was necrotic).

${ }^{y}$ Means in the column followed by a different letter are significantly different at $P \leq 0.05$ by Duncan's multiple range test.

The Ca concentration of leaf U1 in the control group was only $0.05 \%$. By simply unfolding this leaf artificially, Ca concentration was increased 4 -fold to $0.20 \%$; this was statistically significant at $P<0.0001$. The Ca concentrations of all upper leaves in ALU and control plants were $0.94 \%$ and $0.80 \%$, respectively. The difference between treatments in all nonsealed upper leaves was not as significant as that of U1 leaf. This was due to there being about five nonsealed upper leaves in the controls that already unfolded by day 7 .

EFFect of OVERHEAd FAns. It was shown very clearly that airflow was inversely correlated with ULN incidence and severity (Table 5). By increasing air movement above the canopy from 0.09 (control) to $0.97 \mathrm{~m} \cdot \mathrm{s}^{-1}$ (high speed setting), ULN incidence was reduced from $88.3 \%$ to $58.3 \%$, and severity from 12.0 to 6.3 , respectively. The use of overhead fans reduced ULN severity to an acceptable range, between 5.8 to 6.3 (Table 5). Because air movement was not evenly distributed under the fan, each plant received a different air flow. We observed that plants directly under the fan had less ULN than plants on the edge of the chamber.

\section{Discussion}

Table 1 shows young expanding leaves had a lower stomatal conductance than mature leaves. Thus, under the same environmental conditions, these young leaves had a lower transpiration rate and consequently a lower $\mathrm{Ca}$ concentration. These factors made the young upper leaves prone to ULN. It is common that $\mathrm{Ca}$ accumulates as leaves age (Collier and Huntington, 1983). In sorghum, Ca concentration in upper leaves is just $40 \%$ of that in lower leaves (Murtadha et al., 1989). In lettuce, it was also found that $\mathrm{Ca}$ concentration of inner leaves was as low as $0.1 \%$ to $0.2 \%$, only about one-fifth of outer leaves (Thibodeau and Minotti, 1969). Aradioactive ${ }^{45}$ Ca transport study also showed that $\mathrm{Ca}$ in young tomato leaves was much less than in mature leaves (Ho and Adams, 1989). Calcium deficiency is generally restricted to organs or tissues with low transpiration rates and a high demand for assimilates (Bangerth, 1979).

Calcium demand and translocation in crops with a storage organ (such as a lily bulb or potato tuber) may be somewhat different from other crops. However, transpiration is still important, especially in the later growth stage. In 'Star Gazer' lily, ULN does not develop on lower leaves (Chang, 2002), because the bulb is able to provide $\mathrm{Ca}$ in the early growth stage and the shoot also accumulated some $\mathrm{Ca}$ in the previous growing season (Chang and Miller, 2003). As the plant grows, transpiration becomes markedly important for young upper leaves at the stage when the bulb cannot supply sufficient $\mathrm{Ca}$. Under conditions that upper leaves can not have relatively high transpiration, necrosis occurs.
By manually unfolding the upper leaves, we were able to reliably and repeatedly suppress the development of ULN. We demonstrated that leaf enclosure contributed to ULN and high transpiration of upper leaves was an important factor in reducing ULN at this stage (Tables 2-5; 0Fig. 2). Plants treated with ALU were shorter than controls (Table 3 ), likely a thigomorphogenic response. The most common thigmomorphogenetic response is the retardation of stem elongation (Jaffe, 1973), and is believed to be mediated by ethylene (Biro and Jaffe, 1984; Boyer et al., 1986; Telewski and Jaffe, 1986). In our study, ALU, touching, and foliar ethephon sprays all significantly reduced plant height, but only ALU significantly reduced both ULN incidence and severity. For example, plants in the mechanically perturbed group were shorter than the ALU group, but had a high ULN incidence and severity. It is concluded that the main positive effects of ALU in reducing ULN were not due to thigmomorphogenesis per se.

Transpiration rate and $\mathrm{Ca}$ concentration of upper leaves in ALU treated plants were greater than controls (Table 4). The difference on day 7 in transpiration between treatments was less significant compared to the daily water loss $(P=0.05$ and 0.006 , respectively). The reduction of significance at day 7 was due to the fact that about five leaves in the control plants being unfolded by day 7 . The difference of average $\mathrm{Ca}$ concentration of upper leaves between treatments was also not as large as that of leaf U1 (18\% vs. 4-fold increase, Table 4). This is also attributed to the unfolding of leaves and increased subsequent transpiration of the controls. These results again demonstrated that leaf unfolding was important for increasing transpiration, and transpiration was important for $\mathrm{Ca}$ translocation to these young expanding leaves. We conclude that the mechanism of ALU reducing ULN was primarily due to increased transpiration and, therefore increased leaf calcium level.

In the first ALU experiment, plants were grown in a drier greenhouse than the subsequent experiment (35\% RH vs. $51 \%$ ). The incidence of ULN in the first experiment was only $20 \%$, whereas in the second experiment, it was $87 \%$ (Table 2). While it is not possible to compare these values statistically, this observation of reduced ULN at lower RH further demonstrates that increased transpiration is important for suppressing ULN. In lettuce, covering young developing leaves with aluminized polyethylene sheaths decreased leaf Ca concentration and greatly increased tipburn on inner leaves (Barta and Tibbitts, 1986). Thus, the inadequate Ca translocation to upper leaves of 'Star Gazer' lily had a combination of causes: insufficient Ca supply from the bulb (Chang and Miller, 2003), high demands for Ca in rapidly enlarging tissues (Chang and Miller, 2003), low transpiration of these tissues (Table 1), and the physical arrangement of young leaves (leaf enclosure; Tables 2 and 4). Since the internal younger leaves were enclosed by outer (older) leaves, a physical barrier existed that led to low transpiration. Furthermore, the margins of young leaves overlapped each other in a manner that further reduced transpiration. This explains why ULN symptoms generally occur first on the leaf margins. It has been demonstrated in cabbage that $\mathrm{Ca}$ concentration is positively correlated to the transpiration. An actively transpiring outer leaf should have more Ca located at its edges than the veins due to the movement of the transpirational stream (Wiebe et al., 1977). In contrast, a lettuce leaf with tipburn had low $\mathrm{Ca}$ level at the distal margin but higher Ca levels near the midveins (Barta and Tibbitts, 1991b; Barta and Tibbitts, 2000). Results from this study suggest that the overlapping of expanding lily leaves makes the edges have less $\mathrm{Ca}$ and be more susceptible to ULN. We also observed that 
'Star Gazer' lilies grown in outdoor fields of Ithaca, N.Y. exhibited little ULN. This observation further supports the results in this study, as more air flow in the field would increase transpiration. Barta and Tibbitts (1991a) also documented that field-grown lettuce had higher $\mathrm{Ca}$ concentration and less tipburn than lettuce grown in growth chambers.

It was also interesting that foliar ethephon sprays reduced ULN severity to some degree, although not to the degree of ALU. Plant growth regulators have not been reported as a method to control Ca deficiency disorders. How ethephon reduces ULN severity is not known, but it might subtly change leaf orientation, unfolding, stomatal aperture, or growth rate. There are conflicting data regarding the effect of ethephon on stomatal opening (Levitt et al., 1987; Vitagliano, 1975; Vitagliano and Hoad, 1978). It appears to be species dependent (Vitagliano and Hoad, 1978), and ethephon treatment may result in opening or closing of the stomata depending upon the concentration and the time of exposure (Frommhold, 1982). In corn, ethephon increased stomatal density (Kasele et al., 1995). The effect of ethephon on stomatal opening in Lilium 'Star Gazer' is unknown.

Visual ULN Symptoms were developing within a 20-d period, approximately between 30 and 50 DAP. We thus hypothesized that there is a 25-d critical period, between the time when plant height is $\approx 25 \mathrm{~cm}$ and visible bud stage (from $\approx 25$ to $50 \mathrm{DAP}$ ), that ' $\mathrm{Star}$ Gazer' is susceptible to ULN. The idea of this hypothesized critical period is based on the assumption that it may take up to 5 days for visual symptoms to appear, and that no more necrosis is observed after flower buds are visible. We tested our hypothesis by applying ALU treatments during this period. Plant growth rates were highly influenced by environmental factors, thus actual dates for ALU applications in experiments were 20 to 45,24 to 49 , and 31 to 56 DAP respectively as reported in the "Materials and Methods." In all experiments, ULN was almost fully controlled. This indicated that the critical susceptible period is a realistic concept for growers to use and might help in devising practical grower tools to combat this problem.

In the airflow experiments, we used inexpensive, low-power fans to blow air vertically down to the canopy. The results were satisfactory. However, the air flow was not distributed evenly and some plants didn't receive enough air movement. If more or highpower fans were used, both ULN incidence and severity might be further reduced. One other possibility would be to use high-power fans mounted on a movable boom. With such a system, fewer fans might be able to treat more plants as the fans move above the crop. We suggest that overhead fans blowing vertically downward offer a practical means for controlling ULN in lily if proper engineering is used to design a system with uniform airflow.

\section{Literature Cited}

Bangerth, F. 1979. Calcium-related physiological disorders of plants. Annu. Rev. Phytopathol. 17:97-122.

Barta, D.J. and T.W. Tibbitts. 1986. Effects of artificial enclosure of young lettuce leaves on tipburn incidence and leaf calcium concentration. J. Amer. Soc. Hort. Sci. 111:413-416.

Barta, D.J. and T.W. Tibbitts. 1991a. Calcium localization in lettuce leaves with and without tipburn: Comparison of controlled-environment and field-grown plants. J. Amer. Soc. Hort. Sci. 116:870-875.

Barta, D.J. and T.W. Tibbitts. 1991b. Use of electron microprobe X-ray analysis for determination of low calcium concentrations across leaves deficient in calcium. Commun. Soil Sci. Plant Anal. 22:729-753.

Barta, D.J. and T.W. Tibbitts. 2000. Calcium localization and tipburn development in lettuce leaves during early enlargement. J. Amer. Soc. Hort. Sci. 125:294-298.

Biro, L.R. and M.J. Jaffe. 1984. Thigmomorphogenesis: ethylene evolution and its role in the changes observed in mechanically perturbed bean plants. Physiol. Plant. 62:289-296.

Boyer, N., G.d. Jaegher, M.C. Bon, and T. Gaspar. 1986. Cobalt inhibition of thigmomorphogenesis in Bryonia dioica: Possible role and mechanism of ethylene production. Physiol. Plant. 67:552-556.

Bradfield, E.G. and C.G. Guttridge. 1984. Effects of night-time humidity and nutrient solution concentration on the calcium content of tomato fruit. Sci. Hort. 22:207-217.

Chang, Y.C. 2002. Upper leaf necrosis on Lilium cv. Star Gazer-a calcium deficiency disorder. Cornell Univ. (Ithaca, N.Y.) Diss. Abstr. Intl. 63-09B:4077.

Chang, Y.C. and W.B. Miller. 2003. Growth and calcium partitioning in Lilium 'Star Gazer' in relation to leaf calcium deficiency. J. Amer. Soc. Hort. Sci. 128: 788-796.

Collier, G.F. and V.C. Huntington. 1983. The relationship between leaf growth, calcium accumulation and distribution, and tipburn development in field-grown butterhead lettuce. Sci. Hort. 21:123-128.

Collier, G.F. and T.W. Tibbitts. 1982. Tipburn of lettuce. Hort. Rev. 4:49-65.

Everaarts, A.P. and M. Blom Zandstra. 2001. Internal tipburn of cabbage (Brassica oleracea var. capitata). J. Hort. Sci. Biotechnol. 76:515-521.

Frommhold, I. 1982. Effect of ethephon on stomatal opening in detached epidermal strips of tobacco leaves (Nicotiana tabacum L. cv. Samsun). Biol. Plant. 24:303-306.

Goto, E. and T. Takakura. 1992a. Prevention of lettuce tipburn by supplying air to inner leaves. Trans. Amer. Soc. Agr. Eng. 35:641-645.

Goto, E. and T. Takakura. 1992b. Promotion of Ca accumulation in inner leaves by air supply for prevention of lettuce tipburn. Trans. Amer. Soc. Agr. Eng. 35: 647-650.

Guttridge, C.G., E.G. Bradfield, and R. Holder. 1981. Dependence of calcium transport into strawberry leaves on positive pressure in the xylem. Ann. Bot. 48:473-480.

Ho, L.C. and P.Adams. 1989. Calcium deficiency - Amatter of inadequate transport to rapidly growing organs. Plants Today 2:202-207.

Ho, L.C., R. Belda, M. Brown, J. Andrews, and P. Adams. 1993. Uptake and transport of calcium and the possible causes of blossom-end rot in tomato. J. Expt. Bot. 44:509-518.

Jaffe, M.J. 1973. Thigmomorphogenesis: The response of plant growth and development to mechanical stimulation. Planta 114:143-157.

Kasele, I.N., J.F. Shanahan, and D.C. Nielsen. 1995. Impact of growth retardants on corn leaf morphology and gas exchange traits. Crop Sci. 35:190-194.

Kirkby, E.A. 1979. Maximizing calcium uptake by plants. Commun. Soil Sci. Plant Anal. 10:89-113.

Kirkby, E.A. and D.J. Pilbeam. 1984. Calcium as a plant nutrient. Plant Cell Environ. 7:397-405

Levitt, L.K., D.B. Stein, and B. Rubinstein. 1987. Promotion of stomatal opening by indoleacetic acid and Ethrel in epidermal strips of Vicia faba L. Plant Physiol. 85:318-321.

Marschner, H. 1995. Mineral nutrition of higher plants. Academic Press, London, U.K.

Morzadec, J.M., A. Hourmant, J. Corre, M.1. Romancer, A. Cottignies, and A. Migliori. 1998. Black spot of globe artichoke: a calcium-deficiency disorder. J. Phytopathol. 146:79-82.

Murtadha, H.M., J.W. Maranville, R.B. Clark, and M.D. Clegg. 1989. Effects of temperature and relative humidity on growth and calcium uptake, translocation and accumulation in sorghum. J. Plant Nutr. 12:535-545.

Palzkill, D.A. and T.W. Tibbitts. 1977. Evidence that root pressure flow is required for calcium transport to head leaves of cabbage. Plant Physiol. 60:854-856.

Shear, C.B. 1975. Calcium-related disorders of fruit and vegetables. HortScience 10:361-365.

Telewski, F.W. and M.J. Jaffe. 1986. Thigmomorphogenesis: The role of ethylene in the response of Pinus taeda and Abies fraseri to mechanical perturbation. Physiol. Plant. 66:227-233.

Thibodeau, P.O. and P.L. Minotti. 1969. The influence of calcium on the development of lettuce tipburn. J. Amer. Soc. Hort. Sci. 94:372-376.

Vitagliano, C. 1975. Effects of ethephon on stomata, ethylene evolution, and abscission in olive (Olea europaea L.), cv. Coratina. J. Amer. Soc. Hort. Sci. 100:482-484.

Vitagliano, C. and G.V. Hoad. 1978. Leaf stomatal resistance, ethylene evolution and ABA levels as influenced by (2-chloroethyl) phosphonic acid. Sci. Hort. 8: 101-106.

Wiebe, H.J., H.P. Schatzler, and W. Kuhn. 1977. On the movement and distribution of calcium in white cabbage in dependence of the water status. Plant Soil 48:409-416.

Win, K., G.A. Berkowitz, and M. Henninger. 1991. Antitranspirant-induced increases in leaf water potential increase tuber calcium and decrease tuber necrosis in water-stressed potato plants. Plant Physiol. 96:116-120. 